NBER WORKING PAPER SERIES

\title{
STRATEGIC SORTING: \\ THE ROLE OF ORDEALS IN HEALTH CARE
}

\author{
Richard J. Zeckhauser \\ Working Paper 26041 \\ http://www.nber.org/papers/w26041
NATIONAL BUREAU OF ECONOMIC RESEARCH
1050 Massachusetts Avenue
Cambridge, MA 02138
July 2019

Lorae Stojanovic provided excellent research assistance. Albert Nichols, Maryaline Catillon and Anselm Dannecker provided insightful comments. The views expressed herein are those of the author and do not necessarily reflect the views of the National Bureau of Economic Research.

NBER working papers are circulated for discussion and comment purposes. They have not been peer-reviewed or been subject to the review by the NBER Board of Directors that accompanies official NBER publications.

(C) 2019 by Richard J. Zeckhauser. All rights reserved. Short sections of text, not to exceed two paragraphs, may be quoted without explicit permission provided that full credit, including () notice, is given to the source. 
Strategic Sorting: The Role of Ordeals in Health Care

Richard J. Zeckhauser

NBER Working Paper No. 26041

July 2019

JEL No. H21,H24,I13

\begin{abstract}
$\underline{\text { ABSTRACT }}$
Ordeals are burdens placed on individuals that yield no direct benefits to others. They represent a dead-weight loss. Ordeals - the most common being waiting time - play a prominent role in health care. Their goal is to direct scarce resources to recipients receiving greater value from them, hence presumed to be more willing to bear an ordeal's burden. Ordeals are intended to prevent wasteful expenditures given that health care is heavily subsidized, yet avoid other forms of rationing, such as quotas or pricing. This analysis diagnoses the economic underpinnings of ordeals. Subsidies to nursing home versus home care illustrate.
\end{abstract}

Richard J. Zeckhauser

John F. Kennedy School of Government

Harvard University

79 John F. Kennedy Street

Cambridge, MA 02138

and NBER

richard_zeckhauser@harvard.edu 


\section{Ordeals and the Special Nature of Health Care}

In economic terminology, ordeals are burdens placed on individuals that yield no direct benefits to others. An ordeal causes what economists call a dead-weight loss (DWL). Some examples of ordeals include requirements that food stamp recipients go through tedious procedures to enroll, that doctors fill out elaborate forms before expensive procedures, or that disabled individuals have to stay in nursing homes to receive subsidies not available for home care. Positing that the ordeal is purposeful, the goal in each case, often unstated, is to direct scarce resources to more deserving recipients. In many cases, "deserving" means "fewer and more desperate." Stigma may also serve as an ordeal, even if unintended. Thus, for example, there may be some shame associated with receiving care at a free clinic.

The artist who is a child of affluent parents may opt not to go through tedious procedures to get food stamps; the doctor may decide not to fill out forms if the value of the procedure to the patient is not worth the administrative burden; an incapacitated individual with an at-home caregiver may receive more comfortable but much less subsidized home care; and a middle class individual may steer clear of any stigma from care at the free-clinic. Ordeals are often imposed in traditional commercial settings, such as by an employer assessing the commitment of employees, but our concern is with ordeals in the healthcare arena. The ultimate saved resource is usually dollars from the government or from a nonprofit organization concerned with social welfare.

The vast majority of resources in our society - such as television sets, apartments, and lawyer hours - are allocated to the individuals who are willing and able to pay market prices. But 
health care has a different status in American society, and even more so in most other developed nations. Health care is broadly viewed as a right or an entitlement. At time of purchase, expenditures on health care are massively subsidized by others. The United States government pays the overwhelming bill for the poor and the elderly. Most middle-class individuals have health plans that are heavily subsidized by their employers and by tax policy. The consumption of almost all expensive health care is covered by some form of insurance. Hence, a cascade of subsidies spills into most significant healthcare purchases.

The philosophy that underlies identifying health care as special and worthy of heavy subsidy, both through insurance and through the subsidization of insurance premiums, is not our concern here. Rather, we are concerned with the second-best policies that follow when purchases are heavily subsidized. Given that the prices consumers pay are well below the value of the resources they receive, there will be a strong tendency to have health care overused and excessively expensive. The worried well will go to the doctor too often. Slightly injured individuals will go to the emergency room when a walk-in clinic visit would use far fewer resources. And doctors will order excessive tests, since their patients will suffer little financial penalty.

Given these wasteful outcomes, governments and healthcare plans have imposed elaborate sets of rules as to who can seek what care, with what subsidy, and in what setting. Ordeals comprise one strong component of those rules. The often unstated objective of these restrictions in general, and of ordeals in particular, is to direct care to those who will benefit 
from it the most. ${ }^{1}$ However, there may be information that predicts benefit that is unobservable to, or unacceptable to employ by, those delivering the care. Given this situation, an ordeal may be a second-best device that does the sorting that could otherwise be accomplished utilizing full information.

Despite these rules, and the resource-withholding effects of ordeals, our society still spends a vast amount on health care. It consumed $18 \%$ of U.S. GDP in $2017 .{ }^{2}$ Other countries, such as Canada (11.3\% of GDP in 2018$)^{3}$ and the United Kingdom (10\% of GDP in 2016$)^{4}$, spent much less overall. That is despite the fact that, with few exceptions, patients in Canada and the UK are not subject to the copayments and deductibles for doctor visits and hospital stays that limit utilization in the United States. Mean per capita spending on health in the U.S. is also much higher $(\$ 9403)$ than in Canada $(\$ 4641)$ and in the UK $(\$ 3377)^{5}$, albeit in part because input prices for health care are higher. It is not surprising that the waiting time for treatment in those two countries, an exemplar of an ordeal, is much longer than in the US.

\footnotetext{
${ }^{1}$ Ordeals are a first cousin to what economists refer to as signaling devices. See Spence (1973). A famous result in the signaling literature is that, even if college offered no value, individuals might still incur the expense of attending as a way to convey to the market that they are high-quality individuals. In parallel fashion, less affluent individuals may accept suffering a dead-weight ordeal to qualify for a valuable benefit, such as subsidized health care.

${ }^{2}$ See National Health Expenditure Data (2018).

${ }^{3}$ See National Health Expenditure Trends, 1975 to 2018 (2018).

${ }^{4}$ See UK Health Accounts - Office for National Statistics (2016).

${ }^{5}$ See Papanicolas, Woskie and Jha (2018: 1024).
} 


\subsection{When a Burden is Not an Ordeal?}

When calling medical offices, or other organizations, one often has to work one's way through an elaborate phone tree. That is surely a burden on the consumer. But if the medical office, or the other organization is saving more on personnel costs than the caller would pay to engage with a human, then the burden is not an ordeal. Resources are being saved. The primary purpose is to serve efficiency, not to discourage utilization. Hence, such a burden is not an ordeal.

\subsection{Alternatives to Ordeals as Rationing Devices in Health Care}

Ordeals address the need for rationing, given the massive subsidies for most healthcare purchases. But there remain some areas of significant medical expenditure where society continues to rely heavily on the market. In many respects, going to the dentist or to the plastic surgeon is not unlike going to any of the vast array of doctors. However, ordeals at the former are much more modest than they are with most physician encounters. One rarely has to wait long times to see a dentist or plastic surgeon. The respective reasons, I propose, are that dental insurance is less widespread than medical insurance and usually offers less full coverage, and that many plastic surgery procedures are considered to be purely cosmetic, and hence are not covered. No one will be trying to limit the use of services where the consumer pays the full bill.

Viagra presents an interesting subsidies case. In many jurisdictions, it is not covered when used to promote sexual function. Presumably, and perhaps prudishly, in those locales, Viagra is classified as an elective treatment, not unlike cosmetic surgery. However, its purchase is covered if it is employed for many other medical purposes. An efficiency perspective, by 
contrast, would cover Viagra for patients with a high willingness to pay. Presumably, an elaborate application process, perhaps required on an annual basis, could separate the highfrom the low-value users of Viagra.

\subsection{Cost-Effectiveness Analysis as an Alternative to Ordeals}

Healthcare utilization can be restricted in other ways beyond dollars and ordeals. Policy analysts and economists often utilize cost-effectiveness analysis to identify which individuals should be given priority for medical treatments. Two fundamental assumptions underlie the use of this technique: 1 ) it is possible to observe and utilize information known about individuals to quantify the benefits they will receive from a medical procedure; and 2) the objective of healthcare spending, at least within that context, is to secure the greatest aggregate benefit - that is, total benefit across individuals - for the dollars expended. Health benefits in a cost-effectiveness analysis are measured using a metric such as qualityadjusted life years (QALYs). ${ }^{6}$ Cost-effectiveness analysis is relatively straightforward to apply within a class of individuals all receiving the same treatment, for example, the use of an expensive prescription drug. It is more challenging and more controversial to compare across categories, for example, a bone marrow treatment for cancer and the use of that prescription drug. Thus, if the former cost $\$ 200,000$ and yielded one QALY, and the latter cost $\$ 20,000$ and yielded 0.2 QALYs, the drug would offer greater cost effectiveness, namely $0.2 / \$ 20,000>$

\footnotetext{
${ }^{6}$ The use of QALYs as a metric is often debated. See, for example, Goldstein (2016). See also, Zeckhauser and Shepard (1976).
} 
$1 / \$ 200,000 .{ }^{7}$ Cost-effectiveness analysis merely gives a priority order to treatments, without addressing the higher-level question of how much money to spend. In an ideal world, spending would continue until the benefit of the last treatment just exceeded the value of the dollars required. This prescription leads to subsequent questions, such as those regarding the value of a QALY and the qualifications of those who determine that value.

Interestingly, cost-effectiveness analysis is employed in the United States to prioritize preventive services, but not treatments, for example in Medicare (Chambers, Cangelosi and Neumann 2015). Presumably, that is because treatment deals with identified beneficiaries. Preventive services, by contrast, only offer modest expected benefits for those at the margin for receiving them. Hence, the political forces are more powerful in affecting treatment priorities than prevention priorities. These observations are reminiscent of the more common discussion of the excess weight given to identified versus statistical lives.

Ordeals, to a significant extent, are able simultaneously to prioritize access to care while escaping the political forces that would directly influence that ranking of access to treatments. Any potential beneficiary willing and able to endure the ordeal receives treatment. The balancing downside of ordeals, as mentioned, is the dead-weight costs that they impose. We now turn to the way ordeals achieve target efficiency: prioritizing treatment to those getting the greatest benefit from the resources spent.

\footnotetext{
${ }^{7}$ When evaluating cost-effectiveness, it is easier to think of greater being better. Hence, the quotient considered is effectiveness/cost.
} 


\section{Ordeals and Target Efficiency}

In most social policy realms, the primary role for ordeals is to improve target efficiency (Nichols and Zeckhauser 1982). For example, services are allocated to those willing to bear the ordeal, as opposed to providing the services to everyone or selling them through market processes. Such an approach is sometimes used in health care. Consider a health clinic seeking to serve the underserved with four types of potential customers, A, B, C, and D.

Table 1. Intended and Actual Patients at a Health Care Clinic

\begin{tabular}{|l|c|c|}
\hline & Mildly III & Significantly III \\
\hline Middle Class & A & B \\
\hline Poor & C & D \\
\hline
\end{tabular}

If the clinic offered appointments based on willingness to pay, as do most commercial services, groups A and B would be its clients. However, its primary goal is to serve group D. If the clinic sorts customers by charging nothing and letting a waiting line discourage low-value clients, only patients in group D will come. A and C patients are not sick enough to make the ordeal worth bearing. B patients value their time too highly and will pay for swifter care elsewhere. The desired outcome is achieved.

Of course, this initial sorting should also be accompanied by a triage process at the clinic if there is significant further heterogeneity in the group D population. An emergency patient, perhaps having a heart attack, should be moved to the head of the line. Triage can also be 
conducted on the costs of waiting: high waiting-cost individuals get served early. Thus, patients in severe pain might get priority; pregnant women might get moved up.

Many ordeals in health care are employed to control utilization. Given that we vastly undercharge for health care at the point of service, even for rich people, adding an ordeal to a money price has the potential to move society back toward the ideal where the value of a service equals its cost.

Almost anyone who is told to see a specialist about a condition would like to be able to do so in the next few days. Being made to wait, possibly for weeks, sorts out the people whose condition would have improved without care. It is not surprising that, in Canada, the wait time to see an oncologist is 3.8 weeks, but to see an orthopedist for a back problem is as high as 39.0 weeks. ${ }^{8}$ That is because back problems often get better on their own, ${ }^{9}$ whereas there is the likelihood that unattended cancer will grow and spread. With cancers, or other conditions that worsen as time passes, wait time is hardly an appropriate sorting device.

It is important to note that waiting time for health care comes in two forms: waiting at a service facility to be served, such as by sitting at a doctor's office; and waiting until one can get an appointment. We shall refer to them respectively as idle wait (IW) and schedule wait (SW). IW

\footnotetext{
${ }^{8}$ See Waiting your turn: wait times for health care in Canada, 2018 Report.

${ }^{9}$ Coste et al. (1994) found that recovery from acute lower-back pain was more rapid than previously described: $90 \%$ of patients recovered within two weeks and fewer than $2 \%$ developed chronic lowerback pain. It is important to note that the Coste et al. analysis focused on patients with a less than 72hour history of pain; this has become a focus for criticism of that paper. However, this aspect of its analysis may reflect the low percentage of actual pain the worried well experience that evolves into a legitimate chronic condition.
} 
is an ordeal of boredom and inconvenience. SW is an ordeal of pain, discomfort, potential lost wages, and/or possible deterioration before one can receive treatment.

\subsection{Deficiencies in the Waiting Line as a Sorting Ordeal}

Waiting lines, whether of IW or SW, are probably the most commonly employed ordeal in health care. Those lines would achieve target efficiency if those who would benefit most from service were always those willing and able to wait, and if waiting did not have other deleterious effects. Those assumptions are not always correct.

For example, some people who would benefit greatly from care might have high costs of waiting. This would be the case, for example, with a severely sick single mother with three young children. That would also be true for an equivalently sick high hourly earner who is unable to substitute a monetary payment for wait time. ${ }^{10}$

Conversely, some individuals simply have low waiting costs. They might find sitting in a doctor's office and reading a magazine to be a relatively pleasant experience. ${ }^{11}$ Individuals with low wait costs will, even when their conditions are mild, secure medical treatment that sorts patients by a waiting ordeal. In short, waiting time can be effective in promoting target efficiency, that is, in bringing in the high-benefit patients, if all individuals have roughly equivalent wait costs. It will perform poorly if those costs are highly variable, as for example if,

\footnotetext{
${ }^{10}$ In many contexts, it would be efficient to employ both ordeals and monetary payments to sort patients.

11 If the artist cited in relation to the food-stamp example likes to sketch portraits or to compose poetry while waiting, that person's waiting cost may be negligible.
} 
apart from medical condition, anxious patients incur high costs from SW while serene patients incur low costs.

Willingness and ability to wait may also interact negatively with the severity of individuals' conditions. Thus, Carter et al. (2012) found that patients in Canada waiting for the treatment of eating disorders were more likely to drop out of the queue if they experienced longer wait times. As a result, some of the patients who needed care the most - those with the riskiest medical histories - missed receiving treatment.

Individuals may also be poorly equipped to understand a system that sorts patients by waiting time. Eastwood (2008) found that, in New Brunswick, back-pain patients waiting for a consultative appointment on potential surgery feared that calling the office to inquire about their place in the queue would place them lower on the waiting list. Desperate to receive care, these same patients upgraded their telephone services to ensure they would not miss calls from the consultative staff.

Using waiting lines to help allocate resources signals equal treatment and solidarity, and the comforting feeling that resources are going to those who need them the most. Absent analytic thought, such feelings can sometimes lead us astray in policy prescriptions. As many cities become ever more gridlocked, the absence of congestion pricing costs society dearly. A driver who would pay $\$ 2$ to make a trip now when streets are busy, rather than lightly traveled later might be imposing a $\$ 50$ waiting time on others, and might be deterred if charged merely a fifth that amount. If congestion-charge monies collected were rebated to all drivers, all might be much better off. 
The allocation of kidneys for transplantation provides a healthcare example where the use of waiting time may sort poorly. Beyond considerations of match and location, priority for a kidney goes to those who have been waiting the longest. ${ }^{12}$ The condition of patients deteriorates as they wait. Hence, long-waiting patients who get a kidney secure fewer expected QALYs than patients who receive a kidney more quickly. Presumably, ethical extrapolation from other contexts helped to create this system. Prioritizing longer-waiting patients also keeps hope alive, as opposed, for instance, to a system prioritizing recency. However, a system that prioritized most kidneys by recency, but allocated a small fraction by duration would both boost QALY gains from the transplant system and still keep hope alive. ${ }^{13}$

In short, wait time ordeals are far from a perfect sorting mechanism. The critical question in any context is how they perform relative to other methods, the most common alternative being monetary payment, for prioritizing care.

\subsection{Ordeals Apart from Inconvenience}

Inconvenience, such as waiting time or paperwork, is almost certainly the most common form of ordeal in health care. However, any burden that involves a dead-weight loss could serve the purpose. Criminal gangs, fraternities, and some military units require the performance of dangerous and/or arduous acts by those who might want to join, thereby sorting by intensity of preference, and in some instances by skill. But a danger imposition would not make sense for

\footnotetext{
12 There is one exception. In an effort to match long living recipients with long-living kidneys, individuals with an estimated post transplant survival (EPTS) score below $20 \%$, where low is good, are given priority for kidneys from deceased donors expected to be in the top $20 \%$ in terms of longevity.

${ }^{13}$ This assumes that those waiting and hoping get a less-than-linear value from the likelihood of getting a kidney. The probability-weighting function from Prospect Theory HAS precisely this property. See Kahneman and Tversky (1979: 280-284).
} 
health care. However, a less pleasant treatment experience, say in terms of ambience, might help to sort.

The design and use of in-kind programs for medical care is an area where the government spends $\$ 1$ trillion per year. ${ }^{14}$ Yet, economists are quick to point out the disadvantages of inkind versus cash transfers, e.g., subsidizing nursing home care, as opposed to giving cash payments to incapacitated individuals. However, in-kind transfers, such as specific medical treatments, can have an advantage in targeting, being of greater benefit to people with particular conditions. Lieber and Lockwood (2019) evaluated the tradeoff between lesser benefits and superior targeting in the context of Medicaid benefits for home care. They concluded that, for plausible assumptions, the better targeting gains outweighed the lesser benefits losses.

\subsection{Pain, Addiction, and Ordeals that Directly Benefit the Patient STOPPED}

Some ordeals help the patient sort his own care. Having a patient suffer pain is surely an ordeal. Weighing against that, addiction to pain killers has become a prominent policy problem of late. When prescribing pain killers, a responsible physician will be trading off relieving the patient from severe pain and raising the risk of addiction. Thus, patients are commonly asked: "How is your pain on a scale from 1 to 10 ?" If the patient's response is higher on the scale, the pain relief concern should get greater weight. The patient should get a somewhat more

\footnotetext{
${ }^{14}$ Calculation from National Health Expenditure Data (2018).
} 
powerful pain killer, possibly for a longer duration. Whether to bear the ordeal of moderate pain or control it with a pain killer is a decision that must rely on patient input.

The aforementioned wait to get treatment for lower-back pain fits into the same category: the ordeal is beneficial on net. Patients can learn whether they fall into the category of patients for whom waiting and suffering, a short-term ordeal, is better than receiving immediate treatment.

\subsection{Ordeals to Conserve Resources}

Health care, with its heavy subsidies, employs ordeals widely as an efficiency measure to limit the use of healthcare resources. Such use would be merited even in a nation with a completely equal income distribution, assuming that it wanted to insure its citizens against significant health expenses, as efficiency would require.

Many ordeals are designed to tilt individuals to seek care in a cheaper way or a cheaper facility. Many patients would prefer brand name drugs over their generic equivalents. However, many states have laws requiring that generics be dispensed unless patients (and/or their physicians) undertake specific actions - a modest ordeal - to overcome the generic default.

For example, both Medicare and Medicaid automatically enroll qualified participants in "step therapy," a tiered formulary ranging from a low-cost generic tier to a very high-cost brandedspecialty tier of drug offerings. Patients are assigned by default to the lowest tier drug that will treat their condition; they progress up tiers only if deemed medically necessary. ${ }^{15}$ The step therapy system provides two built-in ordeals. First, there is a disincentive to try costly

\footnotetext{
${ }^{15}$ See What drug plans cover | Medicare (2019).
} 
treatments initially; higher tier options, which are more costly for the government to provide, typically have higher co-insurance and co-payments incurred by the patient. Second, default lowest-tier prescriptions can only be overridden if the prescriber files for an exception: this four-page form with a 72-hour response waiting time serves as a disincentive to prescribing more costly medications. ${ }^{16}$

Dupas et al. (2016) conducted a randomized controlled trial on the distribution of chlorine solution in Kenya. One study arm gave residents monthly vouchers that they had to walk to a local market center to redeem, a minor hassle; the other study arm handed it our directly. ${ }^{17}$ The result of the walk-and voucher treatment was a significant reduction in the distribution of chlorine solution, but a trivial reduction in chlorine appropriately used for water treatment to prevent disease.

If an emergency room frequently has long wait times, patients - particularly those with minor ailments - may choose instead to go to a walk-in-clinic where the wait is much shorter. The utilization of health resources is likely much greater in the emergency room setting.

We have argued that an ordeal is often employed in lieu of a cash payment to sort utilization of health care, particularly expensive health care. For example, individuals who would otherwise get care for free might be discouraged by a small co-payment from going to an emergency

\footnotetext{
${ }^{16}$ See Medicare prescription drug appeals and grievances: exceptions (2019).

${ }^{17}$ Distances varied based on participants' home addresses. No average estimate of distance from the voucher redemption service was given, but vouchers were redeemable at the nearest market center for $22 \%$ of study participants. See P. Dupas et al. (2016: 891).
} 
room. ${ }^{18}$ This proved to be the case in a randomized experiment that showed that a small copayment operated almost as an ordeal. Selby et al. (1996) found that such a co-payment between $\$ 40$ and $\$ 55$ dollars (2019 value) - reduced emergency room utilization by $14.6 \%$, compared to control. Behavioral economics has shown us that, even to a single individual, a dollar does not always have the same value. Presumably, those discouraged by the small copayment at the emergency room compared those co-pay dollars to the prior zero co-pay rather than to the high cost of providing the care in an emergency room. ${ }^{19}$

Interestingly, the government often requires care in an expensive facility, as opposed to home care, if a patient or her family is to receive reimbursement. A famous case involved Katie Beckett, a young girl with viral encephalitis, and President Ronald Reagan. Medicare rules required that Katie live in a hospital to receive care. She and her parents much preferred care at home. Eventually, Ronald Reagan learned of this situation. He issued the Katie Beckett Waiver, which allowed severely ill children to receive reimbursement if cared for at home. Such home care in this case actually saved the government significant dollars. Presumably, Katie benefitted significantly, since she lived to age 34, much longer than expected (Willson 2012). If the facility care is much less appealing, even if much more expensive, a requirement that only facilities receive significant reimbursement - a salient case of an ordeal imposed on the patient - could actually save the government (or health plan) money. That would be the case if

\footnotetext{
${ }^{18}$ A small co-payment would be an ordeal if the processing cost was significant relative to the copayment amount. The benefit to the purveyor of service would be small or nonexistent. The payment thus would impose a dead-weight loss.

${ }^{19}$ Pratt, Wise and Zeckhauser (1979: 205), examined telephone price quotes for 39 standardized products. They found that, when mean price doubled, the standard deviation of quoted prices increased by $86 \%$. They concluded that individuals were much less willing to spend 15 minutes searching to save perhaps $\$ 10$ when the price of an item was $\$ 300$ rather than $\$ 100$.
} 
significant numbers of families still opted to provide lightly subsidized or unsubsidized home care. We explore a situation of this sort with nursing home care.

\section{The Economics of Optimal Ordeals}

Posit that, for whatever reason, a good is being provided to individuals for a price of 1 , but costs $\mathrm{K}$ to produce. To avoid severe inefficiencies, an ordeal is imposed to limit demand. The ordeal imposes a dead-weight cost $D$. Thus, a consumer will face the effective price of $1+D$. A key challenge for policy makers is to determine the optimal value of $D$. The answer depends on the elasticity of demand for the good, that is, on how the percentage change in the quantity that is demanded responds to the percentage change in the price. If that response is modest (big), the optimal ordeal should be small (great), since many (few) people will be consuming the good who do not value it highly. The optimal ordeal balances the inefficiency of having people buy the good who value it much less than $\mathrm{K}$ against the dead-weight loss of the ordeal. ${ }^{20}$

Posit that $\mathrm{K}=10$ and that 100 people would buy the good if the price were 10 . Here are some relevant values.

Table 2. Optimal Ordeals and the Elasticity of Demand

\begin{tabular}{|l|r|r|r|r|r|}
\hline \multicolumn{1}{|c|}{ Elasticity } & $\mathbf{2}$ & $\mathbf{1}$ & $\mathbf{0 . 5}$ & $\mathbf{0 . 2}$ & $\mathbf{0 . 1 1}$ \\
\hline Optimal ordeal size & 17.0 & 8.0 & 3.5 & 0.80 & 0 \\
\hline Number of buyers & 30.9 & 111.1 & 149.1 & 140.9 & 129.2 \\
\hline
\end{tabular}

\footnotetext{
${ }^{20}$ Even if individuals are identical, an ordeal may sort within individuals, between their high-value and low-value uses. If one always has to wait a long time in the office for a doctor's appointment, one will avoid low-value visits.
} 
As the example demonstrates, given a heavily subsidized price, an ordeal makes good sense when demand is elastic, but not when it is inelastic. No one will have their gall bladder removed just because the price of the procedure is cheap. Hence, the elasticity is low, and an ordeal would at best be wasteful. But the demand for various cosmetic surgeries would respond strongly to price. Hence, if both types of surgery were heavily subsidized, an ordeal would make sense only for the latter. ${ }^{21}$

Quite apart from ethical concerns, or some principle that makes health care a special good worthy of subsidy, risk spreading provides a solid justification for the subsidization of expensive medical care. Generally, there is a small probability that an individual will have any use for an expensive medical procedure. Hence, before that uncertainty is resolved, individuals will want to buy medical insurance. However, even among those who do need the procedure, some will value the procedure much more than others. Given the heavy subsidy, an ordeal may make sense to discourage the relatively low-value users from seeking the procedure.

Posit that there is an expensive surgery that can help individuals with back pain due to herniated disks. The surgery is only cost-effective for those often in significant pain. Unfortunately, only patients know their own pain levels. It might be worthwhile to impose an ordeal before dispensing the treatment. Thus, the individual may be required to engage in extensive time-consuming exercises over a sustained period as a means to convey that the pain is significant. The exercises will help the condition, suggesting that they are only a quasi-ordeal

\footnotetext{
${ }^{21}$ In fact, few cosmetic surgeries, apart from those addressing birth defects or reconstruction, perhaps because of cancer or burns, are subsidized. One could imagine an ordeal, such as requiring the patient and the physician to write detailed letters to a strict appeals board, whereby individuals who would benefit greatly, perhaps due to their psychological needs, might get subsidized cosmetic treatments.
} 
and they may even be more beneficial if the pain is significant. But a major justification for the ordeal is that it is only likely to be undertaken by those in significant pain.

An ordeal may also be useful even if all individuals have identical preferences, given significant risk aversion and relatively high elasticity of demand. It may be a more efficient way to pay for care than imposing greater financial risk. That is because the ordeal is not additive with payment in the utility function. High values for risk aversion and the elasticity of demand would make ordeals a desirable instrument to limit utilization. If those values were low, ordeals would be undesirable. We should also note that if individuals are poor at assessing the benefit they will get from a procedure, an ordeal attempting to assess value would be still impose burdens, but would offer little sorting benefit.

Whatever the justification for heavy subsidies to medical care, an accompanying ordeal may help to screen high-value beneficiaries apart from low-value beneficiaries. ${ }^{22}$ Ordeals can have highly complex consequences, and those consequences can differ substantially across applications. Given space limitations, we will illustrate in one context.

\section{Ordeals and Nursing Homes Versus Home Care}

"John died peacefully at home, after a long illness." The news is sad, but a common reaction is: "What a fortunate individual." Most of us hope to avoid ending our lives in a nursing home. But many of us have no choice, either because we have no one who can deliver care at home,

\footnotetext{
${ }^{22}$ And within a single individual, as in the numerical example directly above, an ordeal screens those individuals' high-value uses from their low-value uses.
} 
and/or because having the government pay for nursing-home care is too attractive relative to home care, where reimbursement from the government is much more modest.

Nursing home care is a major source of medical expenditure in the United States. In 2018, the median annual cost of adult day health care was $\$ 18,720$. By contrast, the cost of a semiprivate room in a nursing home cost $\$ 89,292 .{ }^{23}$ Care for the elderly is a looming problem in the vast array of middle-income and affluent countries, since their populations are rapidly aging, which implies greater need and less availability of care from children.

There is a complex array of ordeals dealing with government-paid nursing home care. First, as mentioned, there are strict limits on assets and income for both the recipient and the spouse. Thus, for individuals somewhat above these limits, they must endure the ordeal of spending down to these limits. It is an ordeal, since the distortion in expenditures benefits no one. The goal of the ordeal is target efficiency, to keep individuals above such limits from reaping the benefits of a program designed to help the relatively poor.

Posit that the individual has qualified on the income-and-assets basis. The government pays much more through Medicaid for an individual in a nursing home than for supplementary home care. To qualify for this higher level of subsidy, the individual who would prefer to be at home must accept living in the less desirable nursing home facility. This is the second ordeal. In effect, the nature of the service itself plays the role of the ordeal. ${ }^{24}$

${ }^{23}$ See Cost of long-term care | 2018 cost of care report | Genworth (2019).

${ }^{24}$ A physician friend many years ago worked in the emergency room at Bellevue Hospital in New York. He remarked on a particularly gruesome ordeal. Down-and-out alcoholics would feign passing out in the street so they could check into the hospital for a few days for a comfortable bed and decent food. The 
We shall explore the case of nursing homes in somewhat greater detail using hypothetical parameter values. Individuals covered by Medicaid in nursing homes must spend down their assets to be sufficiently poor that their costs must be covered. Posit that residence in a nursing home costs $\$ 100,000 /$ year. A critical question regards the optimal level of subsidy for home care. Such payments could cover aides, but might also pay some stipend to family caregivers or for space in the home.

As the payment for home care increases, more individuals would opt for home care rather than the nursing home, a clear savings to the government and benefit to the individuals who switched. The figure below shows the demand curve for home care as a function of the subsidy differential between the nursing home and home care.

interns would scratch such individuals' breastbones with a hypodermic needle, evidently a very painful procedure, to deter individuals who were conscious from faking to be unconscious. 
Figure 1. Demand for Home Care

Versus Nursing Home Care

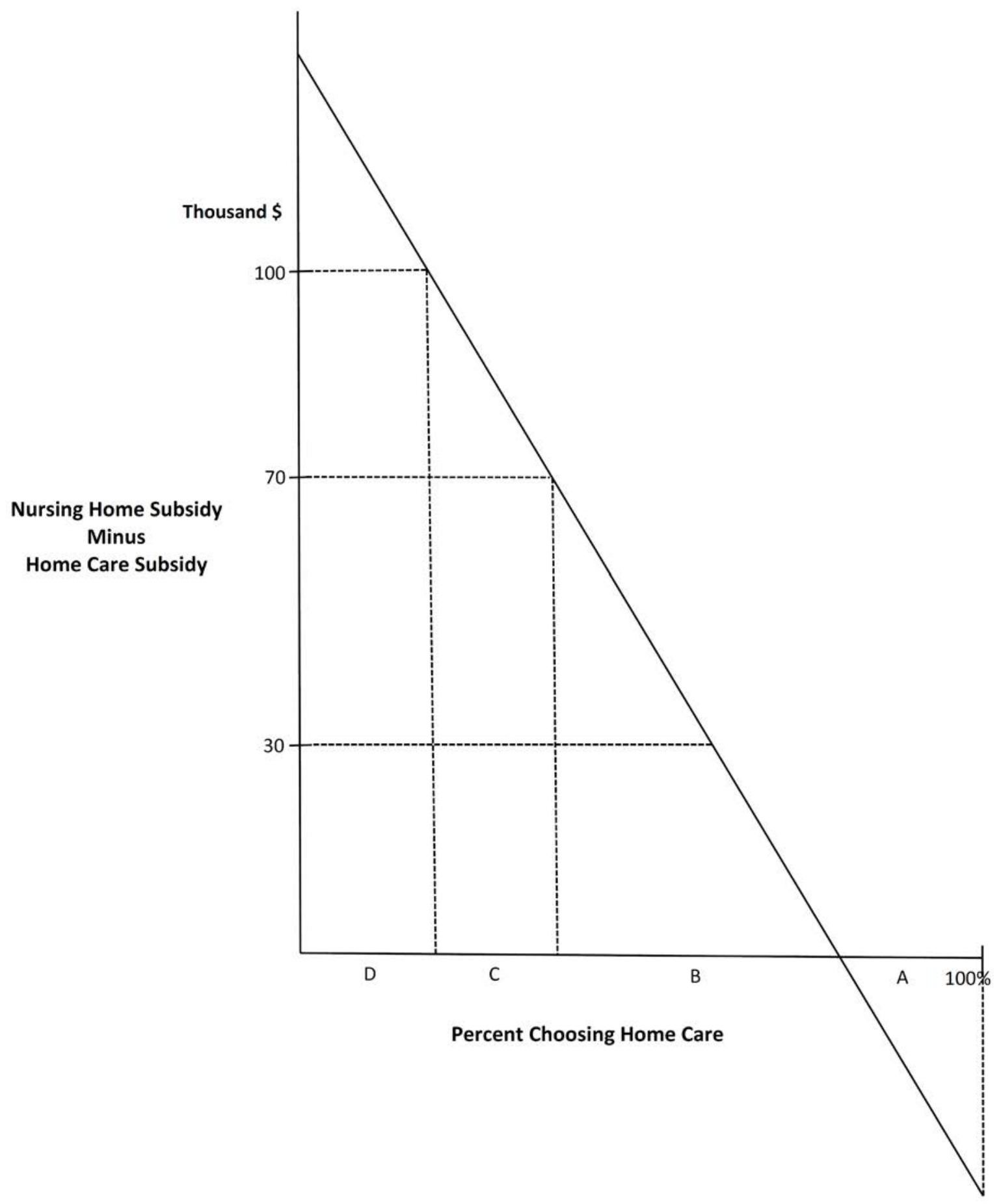


The level of subsidy does not matter for region A. Those individuals will always go to the nursing home. Neither does it matter for region D. Those individuals will always choose home care. Posit that the home care subsidy is $\$ 30,000 /$ year, implying a differential subsidy of $\$ 70,000$. Individuals in $\mathrm{C}$ will choose home care, given this subsidy. Almost all would accept a much smaller subsidy to avoid the ordeal of the nursing home.

Individuals in B will go to a nursing home. They would need a bigger subsidy before choosing to get care at home instead. Obviously, the more responsive individuals are to the home-care subsidy, as is shown by a shallower slope on the demand curve, the larger that subsidy should be. The subsidy is justified because the government saves significant dollars when individuals choose home care, and the switchers avoid an ordeal. The subsidy should be greater if individuals are more responsive, since more will be switching.

Let the number of people in home care be $q$, the subsidy to nursing homes be $s$ per capita, and the subsidy to home care be h per capita. The elasticity of demand for home care at quantity $q$ as a function of the difference between $s$ and $h$ is $e=f(q, s-h)$. Fortunately, the savings when one more person chooses home care is also $s$ - $h$. This implies that the optimal subsidy to home care is where $e=1$, where the fractional reduction in government's savings from home care just equals the fractional increase in people choosing home care.

\subsection{Valuing Government Dollars}

If the government counted dollars of consumer surplus as equivalent to its own dollars, it would subsidize home care to the same level as nursing home care. Then, patients would choose their 
preferred locales. The ordeal of residing in the nursing home to bolster one's subsidy would vanish.

Government agencies tend to value their dollars more than consumer dollars for two reasons. First, most government agencies are concerned with conserving their budgets. They may think that their mission secures great benefits for the dollars involved, or they may just think that prudent spending makes them look good. If so, they will strive to keep people out of nursing homes and in cheaper home care. The ordeal entailed by nursing home living helps them in this effort. They may increase the payments for home care to increase the relative cost of nursing homes, and thus encourage resource-saving switching.

Second, if they think in economic terms, they may recognize that there is a dead-weight cost when government dollars are raised (Saez et al. 2012). Calculating the magnitude of this cost is a complex task. Using 2005 tax return data, Saez et al. (2012: 42) estimate "the marginal excess burden per dollar of federal income tax revenue raised is $\$ 0.195$ for an across-the-board proportional tax increase, and $\$ 0.339$ for a tax increase focused on the top 1 percent of income earners". In the pursuit of efficiency, a government dollar should be valued at (1+marginal excess burden) relative to a consumer's dollar.

This observation makes the burdens that save government dollars, a very common form of burden, more desirable. Even if there were no concerns for target efficiency, an efficiencyseeking government might employ ordeals to discourage the use of services that were priced below their cost of provision. Many health services fall into this category. 


\section{Concluding Thoughts}

Health care at the point of purchase is heavily subsidized in the United States, and more so in other developed nations. This creates an inefficiency situation, where individuals will seek care who would receive little value relative to the resources required. Limiting demand for such care through ordeals, which are impositions on individuals, such as waiting time, that yield no benefit to others, offers a second-best solution. Ordeals enable high-value individuals to receive care while low-value individuals sort themselves out.

Ordeals spring up as a natural response when underpriced resources are made available. Providers, who are losing money on each unit purchased, find ways to limit demand. Common ordeals include making purchasers wait and imposing administrative burdens on them in order to get served. Both are common features in health care.

Prudent policy makers will look for alternatives to heavy dead-weight ordeals as ways to limit demand. Cost-effectiveness prescriptions simply rule out individuals with characteristics that indicate low benefit from receiving treatment. An alternative ordeal may be found where the sorting benefit is the same, but the dead-weight cost is less. For example, a clinic could sort patients by requiring volunteer hours, a clear external benefit, as a price for receiving treatment. Or, as mentioned, back patients could be required to do extensive exercises, a benefit to themselves but one they might not otherwise reap, before becoming eligible for an expensive surgical procedure.

Ordeals highlight an intriguing principal-agent relationship between doctor and patient, with the usual complexities of principal-agent relationships. This analysis focused on situations 
where the patient, or the patient's family, is the decision maker. However, doctors often play a major role in determining where and how a patient is treated. Nevertheless, ordeals may still play a valuable sorting role. Sometimes an ordeal will be suffered by the patient, say who must wait in line at a medical facility, where the doctor's concern for the patient's welfare does the sorting. Other times, the doctor will bear the ordeal, say by having to fill out extensive paperwork to qualify a patient for a procedure.

Ordeals, such as waiting lines or tedious application processes for underpriced resources, spring up naturally and did so long before any theory explaining their use. But that an ordeal is natural and existing hardly implies that it is optimal. Moreover, the evolution of ordeals toward superior arrangements may be sluggish. That evolution is slowed down by the inertia imposed by those who enjoy the current arrangements and by the disproportionate influence of entities that are already in place. Those stay-put forces are reinforced by ethical arguments and behavioral propensities, both of which weigh costs from acts of commission far above costs from acts of omission.

Although the use of ordeals in a variety of settings stretches back for eons, their widespread use to sort individuals receiving subsidized healthcare is a relatively recent phenomenon. Unfortunately, those setting ordeals in healthcare are only loosely concerned with their optimal use. Too often indeed, ordeals are treated as natural phenomena, with little thought that they might be replaced or improved. ${ }^{25}$ Those who foster an ordeal, say the manager of a health plan

\footnotetext{
${ }^{25}$ Beside inattention, an uncompensated positive externality leads to insufficient efforts to improve ordeals. If A develops a superior arrangement, B can easily imitate it without paying compensation. Business practices such as waiting line design cannot be patented.
} 
or head of a hospital, may tally personnel costs, insurance revenues and patient revenues to the dollar, but never seek even a crude assessment of the costs and benefits deriving from an ordeal.

Ordeals currently play a prominent and critical role in directing resources to high-value users of health care. Unlike pricing, the primary instrument of resource allocation in developed societies, ordeals are scarcely studied, little understood, and often accepted without thought. Ordeals bring considerable net value to the healthcare system, but conscious attention to their design and operation could greatly enhance that value.

\section{REFERENCES}

Carter, O. et al. 2012. Increased wait-list time predicts dropout from outpatient enhanced cognitive behaviour therapy (CBT-E) for eating disorders. Behaviour Research and Therapy 50: 487-492.

Chambers, J.D., M.J. Cangelosi and P.J. Neumann. 2015. Medicare's use of cost-effectiveness analysis for prevention (but not for treatment). Health Policy 119: 156-163.

Coste, J. et al. 1994. Clinical course and prognostic factors in acute low back pain: an inception cohort study in primary care practice. British Medical Journal 308: 577-580.

Cost of long term care | 2018 cost of care report | Genworth. Accessed March 28, 2019, https://www.genworth.com/aging-and-you/finances/cost-of-care.html.

Dupas, P. et al. 2016. Targeting health subsidies through a nonprice mechanism: a randomized controlled trial in Kenya. Science 353: 889-895.

Eastwood, D. 2008. Experience of adults with low back pain awaiting consultation with a spinal surgeon. 62-63. Library and Archives Canada (Bibliothèque et Archives Canada).

Goldstein, D.A. 2016. Using quality-adjusted life-years in cost-effectiveness analyses: do not throw out the baby or the bathwater. Journal of Oncology Practice 12: 500-502.

Kahneman, D. and A. Tversky. 1979. Prospect theory: an analysis of decision under risk. Econometrica 47: 263-291. 
Lieber, E.M.J. and L.M. Lockwood. 2019. Targeting with in-kind transfers: evidence from Medicaid home care. American Economic Review 109: 1461-1485.

Medicare prescription drug appeals and grievances: exceptions. Centers for Medicare and Medicaid Service, March 5, 2019, https://www.cms.gov/Medicare/Appeals-andGrievances/MedPrescriptDrugApplGriev/Exceptions.html.

Musumeci, M. and K. Young. 2017. State variation in Medicaid per enrollee spending for seniors and people with disabilities. The Henry J. Kaiser Family Foundation (blog), May 1, 2017, https://www.kff.org/medicaid/issue-brief/state-variation-in-medicaid-per-enrollee-spendingfor-seniors-and-people-with-disabilities/.

National Health Expenditure Data. Centers for Medicare \& Medicaid Service, December 11, 2018, https://www.cms.gov/research-statistics-data-and-systems/statistics-trends-andreports/nationalhealthexpenddata/nationalhealthaccountshistorical.html.

National Health Expenditure Trends, 1975 to 2018. Canadian Institute for Health Information, n.d., 4, https://www.cihi.ca/sites/default/files/document/nhex-trends-narrative-report-2018en-web.pdf.

Nichols, A.L. and R.J. Zeckhauser. 1982. Targeting transfers through restrictions on recipients. American Economic Review 72: 372-77.

Papanicolas, I., L.R. Woskie and A.K. Jha. 2018. Health care spending in the United States and other high-income countries. Journal of the American Medical Association 319: 1024-1039.

Pratt, J.W., D.A. Wise and R. Zeckhauser. 1979. Price differences in almost competitive markets. Quarterly Journal of Economics 93: 189-211.

Saez, E., J. Slemrod and S.H. Giertz. 2012. The elasticity of taxable income with respect to marginal tax rates: a critical review. Journal of Economic Literature 50: 3-50.

Selby, J.V. B.H. Fireman and B.E. Swain. 1996. Effect of a copayment on use of the emergency department in a health maintenance organization. New England Journal of Medicine 334: 635642.

Spence, M. 1973. Job market signaling. Quarterly Journal of Economics 87: 355-374.

UK Health Accounts - Office for National Statistics. Office for National Statistics, accessed April 22, 2019, https://www.ons.gov.uk/peoplepopulationandcommunity/healthandsocialcare/healthcaresyst em/bulletins/ukhealthaccounts/2016.

Waiting your turn: wait times for health care in Canada, 2018 Report. Fraser Institute, December 4, 2018, http://bit.ly/2rgVT6B. 
What drug plans cover | Medicare. The Official U.S. Government Site for Medicare, accessed April 29, 2019, https://www.medicare.gov/drug-coverage-part-d/what-drug-plans-cover.

Willson, P.D. 2012. Remembering Katie Beckett. Pediatric Nursing 38: 227.

Zeckhauser, R. and D. Shepard. 1976. Where now for saving lives? Law and Contemporary Problems 40(4): 5-45. 